\title{
Big Data in Healthcare - Opportunities and Challenges
}

\author{
Adriana Gabriela ALEXANDRU, Irina Miruna RADU, Mădălina - Lavinia BIZON
}

The Bucharest University of Economic Studies, Romania

adriana.alexandru811@gmail.com, bizonlavinia@gmail.com,miruna.radu@outlook.com

Healthcare system has evolved once with technology, trying to improve the quality of living and save human lives. Big data is nowadays one of the most important domain of future technology and has gain attention of the healthcare system. This article investigates the advantages and disadvantages of using this technology in healthcare, as they are perceived by the publications and media. To achieve this aims, this paper analyze different documentation and underline the important aspect presented in there. This study can be used as an overview on how big data is noticed by the large public and how is used in saving lives.

Keywords: Big data analytics, Health care, Opportunities and Challenges in Healthcare, Analytics

1

\section{Introduction}

The exponential rate with which the digital data is growing, transforms the world we are living in at every step by presenting both challenges and opportunities. Influencing different domains from science to media, healthcare to gaming, business to IOT is how the data has earn an important place in today modern development for technological progress.

According to a study realized by IBM Marketing Cloud [1], 90 percentages of the data existing today on the Internet has been produced since 2016. Everything around of us is a factory of data, factory that it's creating every day more than 2.5 quintillion bytes of information. Giving thought to that people learned how data can help with previsions and narrowing decisions and that they are enthusiastic in using different sensors to figure out more about themselves and the world around them, it is not a surprise that it is estimated for the rate of growing of date to accelerate the rhythm. All of these masses of data define the phenomenon known as big data. Without a globally accepted definition of big data, the term is used to outline data that is defined by a large variety of type, a rapid rate of producing and transforming, as well as an exponential scale of growing.

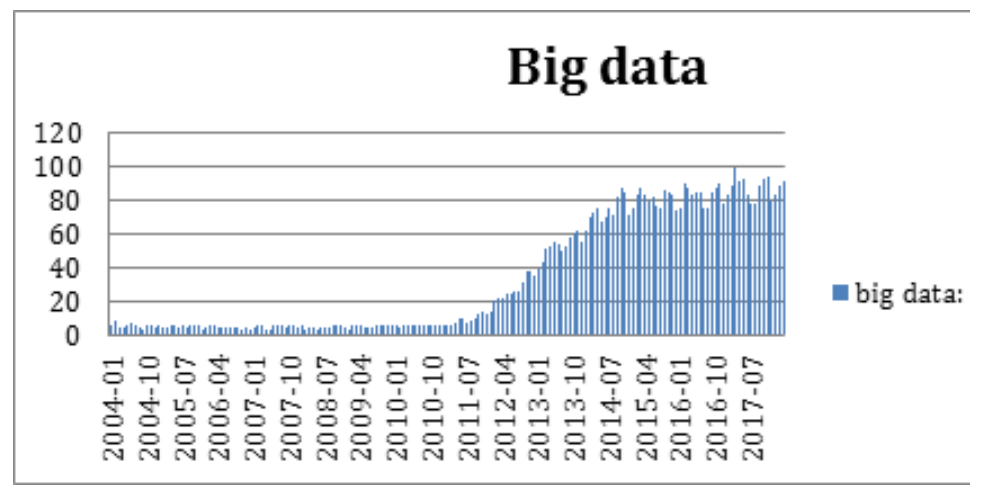

Fig. 1. Big data interest over time [2]

In view of the increasingly popularity of big data, this phrase has become a catchword emphasize at conferences or technical meetings. Looking to the date procured from Google Trends we can see that in the last 2 years big data was a big search term on Google having it's pick in March 2017 (figure 1). Remarkably, big data became a keyword for defining a company that it's looking for the future, for something great being one step 
before everyone else, trying to innovate, or even for a domain to evolve and set up a new trend for others. As a result more and more companies tries to implement a use for big data in their company no matter if they know what to do with it or not, they needed or not [2].The companies that desire to somehow gain a competitive advantage by implementing big data analyses, they need to keep in mind of the challenges and opportunities that can appear and to always keep their eyes on the prize: gaining business value without losing the minds of managers and employees, destroying lots of storage and overpaying for something that may not help. More and more studies are trying to outline the benefits of big data regarding on how they can improve the quality of user experience through applications and implicitly improving the way human live their life. One important subject tackled by studies are the usage of big data generated by the sensors, that are nowadays everywhere around us. In [3] and [4] emphasize the way big data regarding location can be used for a personalize user experience. What is more, [5] combined lots of GB of data to find out more about the influence of weather in people mobility routes, the influence of different places in the level of intimacy and safeness, the migration in the perspective of distance from friends and acquaintances. More recent applications use big data regarding of the mobility of people to present the distribution of population through visual boards like maps [6], [7] or to recognize and acknowledge the habit of patterns in cases of emergency, like the ones generated by natural disasters, or for the ones that are not emergencies like holidays and other celebrations.

Big data can be used in different domains like from forensic science and medicine as [8] and [9] points out to ethics as described by [10], from IOT as [11] presents to social science as showed in [12].

In healthcare, big data refers to electronic health data sets that are so complex and large, things that make difficult or even impossible the management of all that information with any traditional software or hardware or using common data management tools [13]. In [14] the promise and the potential are exposed as being the transformation of the way healthcare providers gain knowledge and insight from their clinic with the use of new technologies and make smart decisions. And most of the times the health system doesn't really required big data, like the case of precision public health pointed out by [15], but using it can uncover more knowledge and capabilities that will put the healthcare system in a user friendly environment.

Even though big data has won a big reputation [16] outlines three of the major problems big data presents and everyone should be aware of. First one is regarding the right to privacy, more explicit to data privacy, because no one it's really in control of how much of our personal information is out there for processing and analyzing. Second one is referring to data security, which if we think better about it was a problem for some companies even before of adding the factor of big data. This way the existing security breaches multiply in an exponential rate. Last one is indicating to data discrimination, the fact that based on an analyze people receive different information, and make other resources hard to access for others. This issue is underlined in [17] where the Federal Trade Commission presents the concerns that companies may expose a different price for the trading goods having in mind different zip codes according to the range of income. They also argue that big data will give companies some new instruments to justify exclusion of certain individuals from particular opportunities.

But all of this does not imply that the companies should use big data just because it's a trend and you need to be on the latest technology train. Even though as shown above, big data used in a mannered way can expose critical information, there are always risks in a way that will not outweigh the value gained.

This article aims to outline how the healthcare domain is using big data through its advantage, innovating for people and improving the healthcare system. Therefore, 
the goal for this paper is to bring to surface the advantages that are outline most of the time in articles or publications, revealing how big data in healthcare is perceived in the ,,world wide web" world through the ingeniously of the solution implemented. The disadvantages are not lost through the focus, being presented through real life cases, where big data in healthcare journey got into a bump in the road. It is expected that this article will enrich the cultural expertise of people reading it on what big data can do for the healthcare systems and pave a way for future researchers to create a timeline of the healthcare evolution through technology, taking into consideration the issues and opportunities, barriers and challenges that appeared along the road.

\section{Literature review: Big Data in Healthcare}

There have been big volumes of information gathered by the healthcare industry over the years. A large amount is kept in hard copies, but nowadays, the virtual storage is used. These huge amounts of information are called Big Data, whose purpose is to improve healthcare's quality by diminishing the expenses that come along. Bid Data promises supporting several aspects of healthcare such as medical functions which refer to disease observation, the management of people's health and medical decision support.

Big Data identifies connections and understands directions and patterns within the information, and, as a result, care is improved, lives are saved and, an important aspect diminishes costs and expenses. In doing so, Big Data in the healthcare domain makes use of the explosion of information to make better decisions. It is also a research group, so healthcare is an important field to be analyzed. After Big Data being analyzed and observed and the previously talked about connections, patterns and directions being exposed, the ones that offer healthcare services and those dealing with healthcare delivery system can work and discover new diagnoses and healing programs, which would eventually lead to more qualitative care activities which cost less but bring more results.
The possibility for Big Data to lead to better results in the case of healthcare is to be seen in several situations such as: by examining a patient's particularities and the expenses and consequences of health in order to discover the most adequate treatments regarding costs and medical purpose and to offer analysis and instruments, having a huge influence on the supplier; analyzing the patient's profile in an advanced manner (which refer to segmentation and diagnose) in order to identify people who would be offered preventative attention or modifications in one's style of life; profile of disease on large variety in order to discover potential events and support research actions; gathering and releasing information about medical actions and processes, helping the healthcare patients find the best valued procedures; observing, researching and diminishing fraud my establishing an effective system that could identify fraud and verify the validity of a claim; applying claim authorization; realizing new benefit directions by associating a patient's medical records and claims in order to supply third parties with data, which could eventually lead to patients identified by pharmaceutical industry to participate in clinical experiences.

Many payers are trying to implement applications that can be installed on a mobile phone that help users be attentive to their health, identify suppliers and improve their own health. By means of this action, payers are able to actually observe their bodies' response to medicines and treatment, but also observe the directions whose final result leads to people's benefits individually and globally. Big Data enables disease observation which would lead to the possibility to know quicker than the traditional method of scientific research. Huge volumes of information found in thousands to millions of information points (individuals, medical situations, medical receipts) can rapidly generate data. By recording them, symptom, drug, disease or medical procedure and by observing the resulting information and the movement of pathogens, disease attitude towards treatment and drugs can be achieved. Having access to 
Big Data may lead to the understanding of a disease's causes and consequences, but also to possible methods of improving. The recording similar anterior situations may lead to a future diagnosis, but also to an understanding of its success in this program. The disease causes can be better understood, and the more adequate treatments can be given to rapid identified patients, which have a big risk of disease.

Phenotype and disease category represent an essential challenge in precision medicine. If a group of patients having the same or similar issues can be classified into appropriate subtypes, more effective personal treatment comes very handy. Subclassification is also a strong instrument for translational research, as classifying people relying on differences in deep phenotypes can have a result in better patient selection for medical procedures and experiences, but also in participation to other researchers such as GWAS.

Researches have been efficient using mobile phone information in recording movement in cholera, malaria, dengue, human immunodeficiency virus (HIV), Ebola, rubella, and schistosomiasis. Other programs that have been efficient or may be efficient in recording movement of sick people include air travel information, GPS data-loggers, magnetometers, Twitter, and web entering.

Big data appears as a concept in a lot of industries, including healthcare. There are expenses of millions of dollars on recent technology. They make use of sophisticated algorithms which can tell one's future healthcare necessities based on personal customs and anterior appointments with medical staff. It is both strong and risky. In Bates et, 2014 also show an analysis where the accent is using for the hospital to figure out how to reduce the cost that according to their research are really high in US. Taking all this into consideration big data has several pros, but its cons are also important.

According to [18] when talking about big date in healthcare there is always the problem of sensitive being made public and this way everyone should really carefully think to the risk-benefit ratio. And also accordingly to
[19] another problem identified is the fact that we are standing in a point where in time where companies do not share all the data in a compatible format that can be fully analyzed. From her side the full potential of big data in healthcare can only be achieve after the organization start to invest more time and work into sharing of data between them.

In [20] analyze the way big data in healthcare from the perspective of patients, hospitals and governments which can all benefit from introduction big data in healthcare.

\section{Research Method}

This research method is based on several stages: searching for similar studies, evaluating them and using the needed information.

The first stage in finding similar studies is to indicate principal keywords [21]. Some important documents released since 2010 were studied in the domain of information in general and in regards to healthcare and the system of decision making. It has discovered that there are several important keys that used in connection to technology support the system of medical data.

The next two steps were applied in searching for significant documents in several databases. Those papers should contain some keywords such as "analytics", "healthcare", "big data", "decision making" or another related to healthcare.

In order to accomplish the purpose of the present study, we made use of quantitative method in the sense that we analyzed a large number of cases. This was made to understand and correctly classify Big Data's capacities to analyze and one's possible advantage by using its functions. The situations analyzed were drawn from either present or precedent projects or from various sources such as journals, printed documents, case files and even recordings from administrative units, merchants, consultants and analysts. There is indeed a lack of academic sources in our project, but it is only because in the healthcare domain the matter has not been discussed too much yet. 
For this study we choose a quantitative approach to complete our goal. More precisely we analysis multiple research papers to have an overview and understanding on how big data in healthcare is perceived through the advantages and disadvantages.

\section{Paper selection}

For our selection we used big data projects with documentation from 2000 up to now as presented in online or printed publication, scientific journals and reports from vendors or companies. In creating our collection we opt for paper that presents the advantages and disadvantages of big data in healthcare and haven't been already obsoleted by the passing of time. We did not take into consideration reports that were made by the companies themselves and where the information was more a marketing schema. Also the journals that were outdated were also excluded. At a total we managed to select 9 papers that were according to our needs of outlining the advantages and disadvantages of big data through a critical point of view. From these papers 6 were scientific journals and the rest were other types of publications.

\section{Process}

After selecting those articles and projects from different conferences on the given theme, we continued extracting the advantages and disadvantages of each study, keeping in the end only those found in the majority of the documents, having thus uniformity and harmony.

Table 1. Results

\begin{tabular}{|c|c|c|c|}
\hline $\begin{array}{c}\text { Opportunities } \\
/ \\
\text { Challenges }\end{array}$ & Category & Description & Citations \\
\hline \multirow[t]{6}{*}{ Opportunities } & $\begin{array}{l}\text { Upper } \\
\text { qualitative care }\end{array}$ & $\begin{array}{l}\text { The sole purpose of big data is the } \\
\text { improvement in healthcare services by } \\
\text { giving the doctors the possibility to make } \\
\text { exact predictions upon a patient's } \\
\text { condition based on his well recorded } \\
\text { previous medical history and algorithms } \\
\text { which analyses his lifestyle }\end{array}$ & $\begin{array}{l}{[19] ;[20]} \\
;[21]\end{array}$ \\
\hline & $\begin{array}{l}\text { Indication of } \\
\text { Fraud }\end{array}$ & $\begin{array}{l}\text { Fraud can occur in the case of hospital } \\
\text { visits and requests from various health } \\
\text { opportunities. More than that, medical } \\
\text { verdicts, tests and their results, medical } \\
\text { treatment and other items can be analyzed } \\
\text { and thus indicate possible medicine abuse. }\end{array}$ & $\begin{array}{l}{[22] ;[23] ;} \\
{[24]}\end{array}$ \\
\hline & $\begin{array}{l}\text { Advanced } \\
\text { Patient } \\
\text { Attention }\end{array}$ & $\begin{array}{l}\text { Analysis in healthcare field can help } \\
\text { doctors and medical staff make more } \\
\text { optimized decisions and offer individual } \\
\text { and personalized attention to patients. }\end{array}$ & $\begin{array}{l}\text { [25]; [26]; } \\
{[27] ;[28]}\end{array}$ \\
\hline & $\begin{array}{l}\text { Upgrade } \\
\text { operational } \\
\text { proficiency }\end{array}$ & $\begin{array}{l}\text { Early analysis is important in offering } \\
\text { better attention and care and diminish the } \\
\text { costs. }\end{array}$ & $\begin{array}{l}\text { [29]; [30]; } \\
{[31] ;[32]}\end{array}$ \\
\hline & $\begin{array}{lr}\text { Discovering } & a \\
\text { remedy } & \text { for } \\
\text { illnesses } & \end{array}$ & $\begin{array}{l}\text { Information from different subjects is } \\
\text { analyzed by using machines and maybe a } \\
\text { cure can be found on both general and } \\
\text { individual cases }\end{array}$ & $\begin{array}{l}\text { [33]; [34]; } \\
{[35]}\end{array}$ \\
\hline & $\begin{array}{l}\text { Reduce costs } \\
\text { and times of wait }\end{array}$ & $\begin{array}{l}\text { Improving productivity in healthcare } \\
\text { industries by making clever use of the } \\
\text { human and financial resources which are } \\
\text { available, and also establishing better }\end{array}$ & $\begin{array}{l}{[36] ;[37] ;} \\
{[38]}\end{array}$ \\
\hline
\end{tabular}




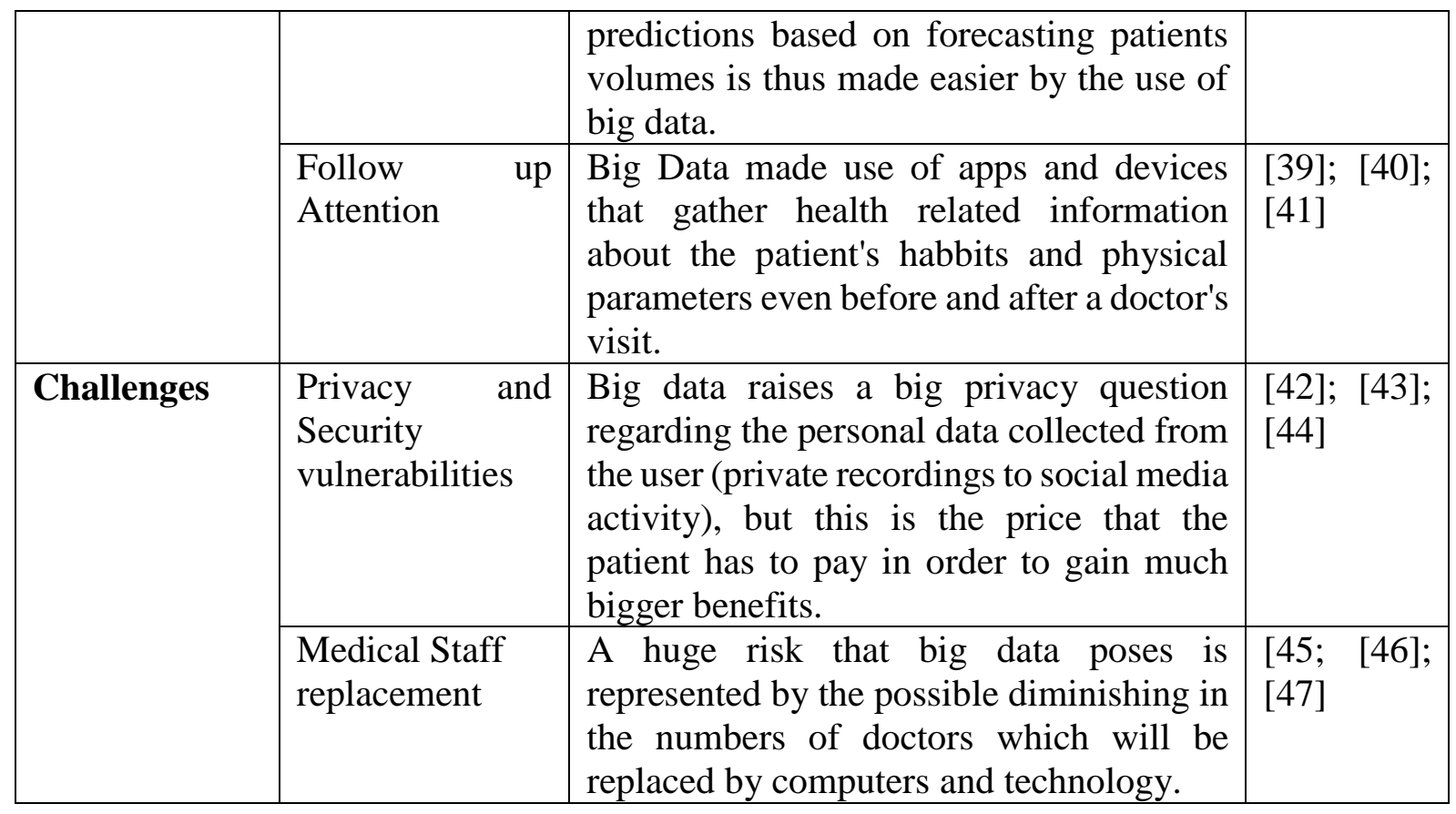

\section{Results}

The results of this research are here to underline how big data is seen through the eyes of the world. The most important opportunities and challenges are listed below with real life examples

\section{OPPORTUNITIES}

\section{Upper qualitative care}

Big data relies on different sources such as previous meetings with doctors, social media and exterior activities. As a result, it creates a structured picture of the client. The traditional methods of physical charts completed by employees with their online courses brought a little amount of information regarding personal life and charts. Nowadays, there is a huge amount of information leading to the healthcare suppliers' knowledge about what helps a person lose weight. As an example, if someone is fond of skiing and this is to be seen on its social media, a doctor can virtually reach that person's background and indicate the cause of a leg pain. Otherwise, with superficial programs, the doctors will not have enough information.

The general purpose of Big Data in the healthcare domain is to analyze, identify and solve medical problems before they come to represent serious problems. Big Data makes the whole procedure efficient. As an example, an individual seeing a doctor when wanting lo lose weight could be told to take pills for high cholesterol. If that person posts on different social media about modification in its life that stresses, the big data algorithm could make an analysis on that information and indicate the patient with a risk for a heart attack. The doctor can slightly modify the cure to prevent the heart attack, thus solving the problem before it comes to be a real life risk. Big data can have access to DNA records to understand if a patient has sick members in his/her family and if that disease could be send biologically to children.

\section{Indication of Fraud}

Fraud has come to represent a growing issue in the healthcare and insurance domains, but it is a reality that there are patients which make claims hoping to be given money in exchange. Big data is important are really useful in solving this aspect because it can use a large amount of information to find differences in written claims and demands and identify the deceitful ones for more analysis. By making use of its sophisticated procedures, Big Data can compare a huge amount of recordings in order to identify mistakes quicklier than humans could do. Medicare actually saved a lot amount of money (approximately $\$ 1$ billion) by using analysis 
of claim via Big Data. The possible way in which Big Data can detect fraud situations is detailed in articles like "Healthcare Fraud Management using Big Data" published on Trendwise Analytics.

\section{Advanced Patient Attention}

Health recordings made electronically are of real help in gathering population and medical information such as lad examination, clinical information, medical problems and conditions, which would further help healthcare providers offer quality procedures. Patient care benefits taken from using Big Data in healthcare are referred to in a research paper from Dataconomy, "5 ways THE HEALTHCARE INDUSTRY COULD USE BIG DATA - AND WHY IT'S NOT".

\section{Upgrade operational proficiency}

Healthcare units make use of Big Data and turn it into a business tactic to analyze historical individual hospitalization and also staff competence. Healthcare companies can lower the costs and still offer quality care by means of predictive statistics. Big Data is also useful in healthcare because it reduces mistakes related to medication by increasing economic and management competence and reduces reentering.

\section{Discovering a remedy for illnesses}

It is well known that, in regards to medication, a specific pill can work for some individuals, but not for some others. More than that, there are a lot of new things to be discovered in an individual, so it is not possible to study a group of people as one individual. Thus, Big Data can be useful in identifying secrete associations, unrevealed patterns by just analyzing huge sets of information. By using automat studying, Big Data can learn about human genomes and discover the appropriate remedy or pills for cancer.

In what patients are regarded, historical information about symptoms, medication, results of drugs is very important when deciding a remedy. Being helped by BDA, the trend is towards creating an individualized cure for an individual based on his genomic information, location, style of life, medical history, response to certain pills, allergies, family background etc. When the genome information is used at its best, a connection can be established between DNA and a specific illness. Only then, the respective cure can be used for this subcategory. The patient has multiple benefits from it: a cure which is effective and appropriate; decisions made in accordance to health issues; early prevention actions; continuous monitoring of a patient's health; individualized treatment; better quality of life and a hope for a longer life.

The hospitals that effectively use BDA techniques on the information present there, can have several advantages: name the individuals which are about to stay a longer period in the hospital or which are going through the cure several times; indicate the people that must stay in the hospital during the treatment. However, health suppliers could go beyond present plans and develop new ones in order to reduce hospitalization. There are several questions whose answers are within the analysis of information using BDA items and procedures: Is the treatment going to have results on patients? Will patients be responsible for a surgery if it is necessary? Is the patient vulnerable to another disease after the remedy? Is there any possibility for the patient to catch the same illness later in life? It is an option for hospital to make more informed decisions if patients do not respond positively to the treatment, if there are more patients in hospitals because of the same disease. Then a hospital would identify the cause of the situation, have more efficient and competitive employees, buy qualitative medication, improve the cleanness inside hospitals, increase the period of time of a treatment, have more people working together, plans for treatment, take opinions into consideration.I

In the case of insurance units, a huge amount of expenses are used by administrations to pay patients' claims. When using BDA, one can analyze, indicate, prevent and diminish the frauds about medical demands.

For a pharmaceutical unit, when using BDA tools, the $R \& D$ have an influence on 
producing drugs and medicines to treat a certain illness in a shorter period of time.

The administration can make use of information regarding population, historical background of an illness, weather, but also information found on social media about some certain diseases like flu, cholera, etc. This huge amount of information can be analyzed to prevent epidemics, taking into consideration the association between weather and a disease. In this direction, one can say that preventive methods will be established. The BDA tools help in increasing the people's observation related to health and the response to illness appearance.

\section{Reduce costs and times of wait}

As in the case of other industries, costs can be dramatically diminished by using Big Data in healthcare. There's also a possibility to decrease wait times - which means money for most people. One hospital in France, Paris, uses predictive examination to get employees. By knowing how many patients will be in the hospital in a certain period of time, the hospital can decide how many employees must be at work for those patients. There are lots of means to reduce costs, but only a few hospitals make use of them.

Hospital money is intricate, and, even though money invested is money gained, some units are not fully confident into putting their money in Big Data. Money can be saved, used to replace old things with new technology or put in other activities.

An example of how big data can benefit hospital budgets is the use of it for forecasting admission rates. Four Paris hospitals have been trialing machine learning system together with big data for such outlooks. Data coming from different external and internal sources including records for 10 years is used for predicting number of patients that are expected to be visiting the hospital in an interval of time. Information from such results can lead to more efficient deployment of doctors and resources. Big data usage for predictive analytics has been a subject of discussion for multiple scientific writings like [37].

\section{Access to remedies, such as chemotherapy}

By analyzing historical and operational cases and conditions, complex procedures can foretell the volume of work and organize appointments so that there are not any gaps in between cures. This action increases chair usage, diminishes the time in the waiting room for patients and reduces the costs of procedures. It is difficult to manage this action without competent information science. As an example, it is hard to order 70 patients for their remedies in a centre that has only 35 chairs to be used. It has no sense trying to solve this issue using a pen, a paper or even an Excel document.

Having enough beds for hospitalized patients represents a narrow direction. Every hospital tries to give a solution for this issue by analyzing daily every patient's health situation, adding some new patients and thinks about some additional ones, then decides if the hospital can deal with patients within its capacity of beds. It is a never-ending action, which is repeated daily, with a hope for a plan.

\section{Follow up Attention}

Big Data also tells which patients are going to follow the doctor's recommendation in order to prevent crowding the hospitals.

There has been great interest lately in devices that reveal how many steps have been taken or how many times the heart beats. This action leads to improve a patient's physical results and engagement. By using this kind of techniques, health can be monitored and issues such as asthma and blood pressure reduced. There are a lot of applications that can tell when a patient does not feel well, if he/she takes his/her medication or how much he/she sleeps, moves or other actions.

The population is rapidly growing in age, and the Japanese combine robotics and remedy and healthcare. Robots are used in different field, from helping elder people living alone, to helping doctors offer medical support to countryside people helping pets dealing with Alzheimer's patients. 
After taking our time with the opportunities that appear once big data is used in healthcare, it is time to focus our attention to the challenges that come along.

\section{CHALLENGES}

\section{Privacy}

The lack of privacy and intimacy is maybe the strongest flaw. In order to be effective, Big Data must access pretty much everything, from private recordings to social media life. But the price is paid because private information is revealed in order to solve health problems. But a patient's freedom is not given to him. However, there are regulations that state a medical recording's privacy, but they are not too taken into consideration since it is thought that the information about a person should not be forbidden when it relates to his/her health. The subject of privacy risks associated with Big Data use cases in healthcare has been tackled in articles like Big data security and privacy in healthcare in [42].

\section{Replace Medical Staff}

Big data presents the advantage to know about possible future health problems, but it has also a huge risk: the doctors are replaced. Big Data is not so performing as to be used without a human touch, but it is feared that, if its use increases, patients would not go to the doctors, but use the technology and undermine doctors' authority.

Big Data in the case of healthcare cannot be rejected because more and more units and companies invest in this growing field. But, one should consider its disadvantages and realize a procedure safe for both doctors and patients. The question whether Big Data can lead to medical staff replacement has appeared as a subject for discussion on major sites like Forbes, Fortune.

\section{Discussions and conclusions}

Leaving in a age where data is produce at every step of the way gives us the opportunity to do so many great things, but also they leave us exposed to many points of failure. As we saw in the results underlined by this research, in healthcare, is really where big data can make a difference and save real human lives. From upper qualitative care to indication of fraud or from reducing the costs and times of wait to discovering a remedy for illnesses and more others were find it out to be the most important advantages of big data in healthcare. The risks of big data in healthcare are not omitted by the publications as it is shown by our study. Privacy seems to be an important problem that people cannot overcome, as well as the replacement of medical staff. This two problems put the large scale adoption of big data in health care under observation.

This research has shed light over the advantages and disadvantages of the use of big data in healthcare. Throughout analytical critics of publications and journals, this paper had identified the most important points in adopting big data in healthcare as seen by publications and journals. The most important findings of this article is that the advantages always overcome the disadvantages, when it comes to saving human life and improving the quality of life.

\section{References}

[1] IBM, "https://public.dhe.ibm.com," 2017. [Online].

Available: https://public.dhe.ibm.com/common/ssi/e $\mathrm{cm} / \mathrm{wr} / \mathrm{en} / \mathrm{wrl12345usen/watson-}$ customer-engagement-watson-marketingwr-other-papers-and-reportswrl12345usen-20170719.pdf. [Accessed 16 April 2018].

[2] D. Blazquez and J. Domenech, "Big Data Sources and Methods for Social and Economic Analyses.," Technological Forecasting \& Social Change, pp. 100113, 2017.

[3] R. Montoliu, J. Blom and D. Gatica-Perez, "Discovering places of interest in everyday life from smartphone data.," Multimedia Tools Appl. 62, pp. 179-207, 2017.

[4] G. Chittaranjan, J. Blom and D. GaticaPerez, "Mining large-scale smartphone 
data for personality studies," Pers. Ubiquit. Comput. 17, pp. 433-450, 2013.

[5] J. K. Laurila, D. Gatica-Perez, I. Aad, J. Blom, O. Bornet, T. Do, O. Dousse, J. Eberle and M. Miettinen, "From big smartphone data to worldwide research: the mobile data challenge," Pervasive Mob. Comput, pp. 752-771, 2013.

[6] P. Deville, C. Linard, S. Martin, M. Gilbert, F. R. Stevens, A. E. Gaughan, V. D. Blondel and A. J. Tatem, "Dynamic population mapping using mobile phone data," Proc. Natl. Acad. Sci., p. 1588815893, 2014.

[7] E. Graells-Garrido, O. Peredo and J. García, "Sensing urban patterns with antenna mappings: the case of Santiago, Chile," Sensors, p. 1098-1123, 2016.

[8] T. Lefèvre, "Big Data in Forensic Science and Medicine.," Journal of Forensic and Legal Medicine, pp. 1-6, 2017.

[9] M. DeLisi, "The Big Data Potential of Epidemiological Studies for Criminology and Forensics.," Journal of Forensic and Legal Medicine, pp. 1-4, 2016.

[10] R. Herschel and V. Miori, "Ethics \& Big Data," Technology in Society, pp. 31-36, 2017.

[11] J. Lee and M. Kang, "Geospatial Big Data: Challenges and Opportunities.," Big Data Research, pp. 74-81, 2015.

[12] H. Liu and G. Guo, "Opportunities and Challenges of Big Data for the Social Sciences: The Case of Genomic Data.," Social Science Research, pp. 13-22, 2016.

[13] F. Sullivan, "https://www.emc.com/," [Online].

Available: https://www.emc.com/collateral/analystreports/frost-sullivan-reducinginformation-technology-complexitiesar.pdf. [Accessed 16 April 2018].

[14] R. Wullianallur and R. Viju, "https://www.ncbi.nlm.nih.gov," 7 February 2014. [Online]. Available: https://www.ncbi.nlm.nih.gov/pmc/article s/PMC4341817/. [Accessed 17 April 2018].

[15] S. Dolley, "https://www.ncbi.nlm.nih.gov," 7 March 2018. [Online]. Available: https://www.ncbi.nlm.nih.gov/pmc/article s/PMC5859342/ . [Accessed 17 April 2018].

[16] B. Marr, "https://www.forbes.com," 15 June 2017. [Online]. Available: https://www.forbes.com/sites/bernardmar r/2017/06/15/3-massive-big-dataproblems-everyone-should-knowabout/\#7617fe776186. [Accessed 17 April 2018].

[17] F. T. Commision, "https://www.ftc.gov," January 2016. [Online]. Available: https://www.ftc.gov/system/files/docume nts/reports/big-data-tool-inclusion-orexclusion-understandingissues/160106big-data-rpt.pdf. [Accessed 17 April 2018].

[18] E. Raguseo, "Big Data Technologies: An Empirical Investigation on Their Adoption, Benefits and Risks for Companies," International Journal of Information Management, pp. 187-195, 2017.

[19] https://vittana.org, "https://vittana.org," [Online]. Available: https://vittana.org/23-advantages-anddisadvantages-of-qualitative-research. [Accessed 2 May 2018].

[20] M. Demetrius and M. Bryan , "https://www.uxmatters.com," [Online]. Available:

https://www.uxmatters.com/mt/archives/ 2012/09/strengths-and-weaknesses-ofquantitative-and-qualitative-research.php. [Accessed 2 May 2018].

[21] V. Konduru, "https://towardsdatascience.com," 9 August 2017. [Online]. Available: https://towardsdatascience.com/theduality-of-data-what-qualitative-datacan-do-that-big-data-cannot3cf3fe52710b. [Accessed 3 May 2018]. [22] K. Venkatareddy, B. Mukul and K. K. Praveen, "Healthcare Fraud Management using BigData Analytics," A Whitepaper by Trendwise Analytics.

[23] "https://www.searchtechnologies.com," [Online]. Available: https://www.searchtechnologies.com/blo 
g/fraud-detection-big-data. [Accessed May 2018].

[23]

P. Nelson,

"https://www.searchtechnologies.com,"

[Online]. Available:

https://www.searchtechnologies.com/blo

g/fraud-detection-big-data. [Accessed 3 May 2018].

[24]

$\mathrm{R}$.

Smith,

"https://revcycleintelligence.com," 14 April 2016. [Online]. Available: https://revcycleintelligence.com/news/usi ng-big-data-in-the-hunt-for-healthcarefraud-waste-and-abuse. [Accessed 2 May 2018].

[25] R. Wullianallur and R. Viju , "https://www.ncbi.nlm.nih.gov/," 7 February 2017. [Online]. Available: https://www.ncbi.nlm.nih.gov/pmc/article s/PMC4341817/. [Accessed 3 May 2018].

[26] H. M. Krumholz, "https://www.ncbi.nlm.nih.gov," 5 July 2014. [Online]. Available: https://www.ncbi.nlm.nih.gov/pmc/article s/PMC5459394/. [Accessed 2 May 2018].

[27] A. E. J. Gemson and S. Durga , "BIG DATA ANALYTICS IN HEALTHCARE: A SURVEY," ARPN Journal of Engineering and Applied Sciences, pp. 3645-3650 , 2015.

[28] K. Tadaaki and I. Hayato, "http://www.fujitsu.com," [Online]. Available:

http://www.fujitsu.com/global/documents /about/resources/publications/fstj/archive s/vol54-2/paper05.pdf. [Accessed 3 May 2018].

[29] S. Uthayasankar, M. K. Muhammad, I. Zahir and W. Vishanth, "Critical analysis of Big Data challenges and analytical methods," Journal of Business Research, pp. 263-286, 2017.

[30]

J. Bresnick,

"https://healthitanalytics.com," 12 June 2017. [Online]. Available: https://healthitanalytics.com/news/top10-challenges-of-big-data-analytics-inhealthcare. [Accessed 3 May 2018].

[31] B. Jiang , M. David , M. Miguel Angel and

$\mathrm{S}$.

Siven "https://www.ncbi.nlm.nih.gov,"

November 2016. [Online]. Available: https://www.ncbi.nlm.nih.gov/pmc/article s/PMC5138448/. [Accessed 3 May 2018]. [32]

A.

Choudhury, "https://www.businesswire.com," 7 February 2018. [Online]. Available: https://www.businesswire.com/news/hom e/20180207005640/en/. [Accessed 3 May 2018].

[33] W. Benjamin , G. Nicolas , H. Yujin and F. Scott L. "https://www.ncbi.nlm.nih.gov," 20 October 2016. [Online]. Available: https://www.ncbi.nlm.nih.gov/pmc/article s/PMC5193106/. [Accessed 3 May 2018]. [34] J. A.Rodger, "Discovery of medical Big Data analytics: Improving the prediction of traumatic brain injury survival rates by data mining Patient Informatics Processing Software Hybrid Hadoop Hive," Informatics in Medicine Unlocked, pp. 17-26, 2015.

[35] Knowledgent, "https://knowledgent.com," [Online]. Available: https://knowledgent.com/whitepaper/appl ying-big-data-to-one-of-the-worldsbiggest-problems-alzheimers-disease/. [Accessed 3 May 2018].

[36] S. a. T. The Pulse on Health, "http://newsroom.gehealthcare.com/,"

[Online]. Available: http://newsroom.gehealthcare.com/trimthe-cost-and-lose-the-wait/. [Accessed 3 May 2018].

[37] V. SARATCHANDRAN, "https://www.fingent.com," 9 January 2018. [Online]. Available: https://www.fingent.com/blog/5-waysbig-data-is-changing-the-healthcareindustry. [Accessed 3 May 2018].

[38] F. Mark and D. Krista , "https://www.soscip.org," 20 Ocotober 2017. [Online]. Available: https://www.soscip.org/big-dataresearch-collaboration-develop-real-timesmart-approach-predicting-cross-borderwait-times-transportation-logisticsindustry/\#. [Accessed 3 May 2018]. 
[39] S. Juran, "http://www.data4sdgs.org/," 1 March 2017. [Online]. Available: http://www.data4sdgs.org/news/leveragin g-big-data-improve-health-outcomes-all. [Accessed 3 May 2018].

[40] A. Pouria, L. Trudie and v. L. Francois, Big Data in Healthcare: Extracting Knowledge from Point-of-Care Machines, Oxford: University of Oxford.

[41] P. Alex , R. Todd G and H. Tracy , "http://www.wish.org.qa," 2013. [Online]. Available: http://www.wish.org.qa/wpcontent/uploads/2018/01/27425_WISH_ BigData_Report_web.pdf. [Accessed 3 May 2018].

[42] . K. P. Harsh and S. Ravi , "Big data security and privacy issues in healthcare," in 2014 IEEE International Congress on Big Data, Dallas, 2014.

[43] A. Karim , B.-H. Abderrahim and K. Hayat, "Big healthcare data: preserving security and privacy," Journal of Big Data, 2018.
[44] K. Hayat , B.-H. Abderrahim and A. Karim , "Big data security and privacy in healthcare: A Review," Procedia Computer Science, pp. 73-80, 2017.

[45] R. Ghosh, "http://analyticsmagazine.org," April 2014. [Online]. Available: http://analyticsmagazine.org/algorithm-is-the-newdoctor-and-data-is-the-new-drug/.

[Accessed 3 May 2018].

[46] K. Gopi, "https://prescouter.com," 22 March 2018. [Online]. Available: https://prescouter.com/2018/03/futuredoctors-office-ai-big-data/. [Accessed 3 May 2018].

[47] T. Sullivan, "http://www.healthcareitnews.com/," 15 May 2017. [Online]. Available: http://www.healthcareitnews.com/news/ machine-learning-will-replace-humanradiologists-pathologists-maybe-soon. [Accessed 3 May 2018].

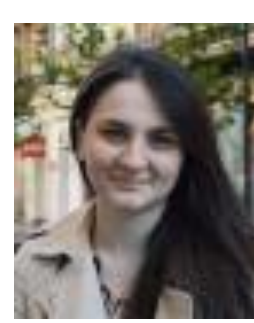

Adriana-Gabriela ALEXANDRU has graduated the Faculty of Cybernetics, Statistics and Economics Informatics in 2016. She holds a bachelor degree in Economics Informatics and now she is following the masters program of Economics Informatics. Currently she is Android Developer at Tremend Software Consulting. She is interested in Mobile Development for both Android and iOS platforms.

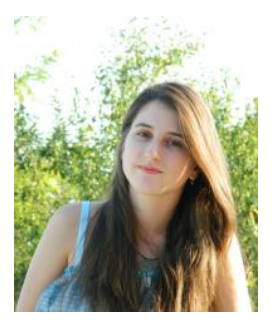

Irina-Miruna RADU has graduated the Faculty of Cybernetics, Statistics and Economics Informatics in 2016. She holds a bachelor degree in Economics Informatics and she is enrolled in the masters program of Economics Informatics. Currently she is Java Developer at Metro Systems Romania. She is interested in JAVA Programming and Business Development.

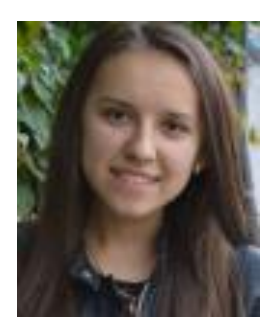

Mădălina-Lavinia BIZON has graduated the Faculty of Cybernetics, Statistics and Economics Informatics in 2016. She holds a bachelor degree in Economics Informatics and she is enrolled in the masters program of Economics Informatics. Currently she is Java Developer at $1 \& 1$ Internet Development. Her objectives revolve around long-lasting studying and personal and professional development in a strong environment and team. She is interested in Full Stack Programming and skills improvement. 